\title{
Physiological characteristics of junior and senior rugby league players
}

\section{T J Gabbett}

Correspondence to:

Dr Gabbett, Sports

Performance Unit,

Tasmanian Institute of

Sport, PO Box 93,

Prospect, Tasmania 7250,

Australia;

Tim.Gabbett@tis.tas.gov.au

Accepted 10 April 2002

\begin{abstract}
Objectives: To investigate the physiological characteristics of subelite junior and senior rugby league players and establish performance standards for these athletes.

Methods: A total of 159 junior (under 16, 15, 14, and 13, $\mathrm{n}=88$ ) and senior (first grade, second grade, and under $19, n=71$ ) rugby league players (forwards, $n=80$, backs, $n=79$ ), competing at a subelite level, underwent measurements of body mass, muscular power (vertical jump), speed (10 m, $20 \mathrm{~m}$, and $40 \mathrm{~m}$ sprint), agility (Illinois agility run), and estimated maximal aerobic power (multistage fitness test). Data were also collected on match and training frequency and playing experience.

Results: There was a significant effect $(p<0.05)$ of age and playing level on playing experience, body mass, muscular power, speed, agility, and estimated maximal aerobic power, with the physiological capacities of players increasing as the playing level increased. Forwards were heavier than backs for all junior and senior teams. Forwards and backs had similar estimated maximal aerobic power, except for under 16 players, for whom significant $(p<0.05)$ differences were detected (mean $(95 \%$ confidence intervals) 42.9 (40.1 to 45.7 ) $\vee 49.5$ (46.4 to 52.6 ) $\mathrm{ml} / \mathrm{kg} / \mathrm{min}$ for forwards and backs respectively). Scores for speed, muscular power, and agility were not significantly different between forwards and backs for any of the junior or senior teams.

Conclusions: The results show that there is a progressive improvement in the physiological capacities of rugby league players as the playing level increases. These findings provide normative data and performance standards for subelite junior and senior rugby league players. Further studies on the sociological, physical, psychological, and personal predictors of talent in rugby league are warranted.
\end{abstract}

$\mathrm{R}$ ugby league is an international sport played at junior and senior levels by amateur, ${ }^{12}$ semiprofessional, ${ }^{3}$ and professional ${ }^{45}$ competitors. The game is physically demanding requiring players to participate in frequent bouts of intense activity-for example, sprinting, physical collisions, and tackles-separated by short bouts of low intensity activityfor example, walking, jogging. ${ }^{6-8}$ As a result, rugby league players must draw upon several fitness components including muscular power, ${ }^{9}$ speed, ${ }^{10}{ }^{11}$ agility, ${ }^{811}$ and aerobic power. ${ }^{11-13}$

The physiological characteristics of professional rugby league players are well developed, with estimates of maximal aerobic power $\left(\dot{\mathrm{V}}_{2} \mathrm{MAX}\right)$ reported to be in the range 48.6-62.6 $\mathrm{ml} / \mathrm{kg} / \mathrm{min} .{ }^{11-13}$ Mean measurements of $10 \mathrm{~m}$ and $40 \mathrm{~m}$ speed of 1.71 seconds and 5.32 seconds have also been reported. ${ }^{9}$ Conversely, the physiological characteristics of amateur rugby league players are poorly developed, with a recent study showing that muscular power, speed, and estimated $\dot{V}_{\mathrm{O}_{2}} \mathrm{MAX}$ were $20-42 \%$ poorer than previously reported for professional rugby league players. ${ }^{14}$ Interestingly, there is a progressive decline in the physiological capacities of professional, semiprofessional, and amateur rugby league players, with estimated muscular power, speed, and $\dot{\mathrm{V}}_{2} \mathrm{MAX}$ of semiprofessional rugby league players superior to amateur players but inferior to professional rugby league players. ${ }^{15}$ These findings suggest a relation between physical fitness and the playing level attained.

Before the age of 13, junior rugby league players compete under modified rules, with a reduced emphasis on physical collisions and increased emphasis on skill development. After the age of 13, the physiological demands placed on junior players are increased, with players required to compete under the same rules and regulations as senior players, with only slight variations in the duration of matches between junior (60 minutes) and senior (80 minutes) players. However, whereas the physiological characteristics of amateur, semipro- fessional, and professional rugby league players have been developed, no study has investigated the physiological profiles of junior rugby league players. In addition, no study has compared the physiological profiles of junior and senior rugby league players. With this in mind, the purpose of this study was to investigate the physiological characteristics of junior and senior rugby league players competing at the subelite level, and establish performance standards for these athletes.

\section{METHODS}

Subjects

A total of 159 healthy male subjects participated in the study. All subjects were registered players from the same subelite rugby league club, and were competing in the Gold Coast Junior Rugby League competition (Queensland Rugby League, Australia) or the Gold Coast Group 18 Senior Rugby League competition (New South Wales Country Rugby League, Australia). Subjects were participants in one of seven teams. Teams competing in the junior rugby league competition consisted of under $16,15,14$, and 13 players $(n=88)$. Teams competing in the senior rugby league competition consisted of first grade, second grade, and under 19 players $(n=71)$. All teams were placed within the best four teams of their respective competitions at the time of the field testing. In addition, all teams but one (under 19) had reached the finals of their respective competitions in the previous season. All subjects received a clear explanation of the study, including the risks and benefits of participation, and written consent was obtained. Parental or guardian consent was obtained before junior players were permitted to participate. The Griffith University ethics committee approved all experimental procedures. 


\begin{tabular}{llll} 
Table 1 & \multicolumn{3}{l}{ Distribution of subjects } \\
\hline Team & Total players & Forwards & Backs \\
\hline First grade & 20 & 11 & 9 \\
Second grade & 29 & 16 & 13 \\
Under 19 & 22 & 10 & 12 \\
Under 16 & 21 & 12 & 9 \\
Under 15 & 23 & 11 & 12 \\
Under 14 & 17 & 7 & 10 \\
Under 13 & 27 & 13 & 14 \\
\hline
\end{tabular}

The total number of subjects was 159,80 forwards and 79 backs.

\section{Procedure}

The rugby league season lasted from December through to September, with matches played from January through to September. All field testing was conducted during the competitive phase of the season (May), after players had obtained a degree of match fitness. The coaches of the various teams within the club stated that they were prepared to devote one training session (about 90 minutes) to the field testing. Although consideration was given to the specificity of the field test, the selection of tests included in the field testing battery was influenced by this time constraint.

\section{Field testing battery}

Body mass, muscular power (vertical jump) ${ }^{16}$ speed ( $10 \mathrm{~m}, 20$ $\mathrm{m}$, and $40 \mathrm{~m}$ sprint), ${ }^{10}{ }^{11}$ agility (Illinois agility run), ${ }^{17}$ and estimated $\dot{\mathrm{V}}_{2} \operatorname{MAX}$ (multistage fitness test) ${ }^{18}$ were the field tests selected. The playing experience of subjects - that is, years of participation-and the training and match frequency were also documented. All subjects had performed the experimental procedures on a number of occasions before the field testing session as part of their team's physical conditioning programme. Players were requested to refrain from strenuous exercise for at least 48 hours before the field testing session and consume their normal pretraining diet before the testing session. At the beginning of the field testing session, body mass was recorded for all subjects using calibrated analogue scales (Seca, Hamburg, Germany). Scales were calibrated using a three point calibration of 20,60 , and $100 \mathrm{~kg}$ weights. Subjects were weighed fully clothed. After measurement of body mass, subjects underwent a standardised warm up (progressing from low to higher intensity activity) and stretching routine. Ad libitum fluid intake was permitted after the measurement of body mass.

Subjects were randomly allocated into three groups, consisting of approximately equal numbers of players. Subjects in group 1 underwent measurements of muscular power (vertical jump), while speed $(10 \mathrm{~m}, 20 \mathrm{~m}$, and $40 \mathrm{~m}$ sprint) was recorded for group 2. Group 3 performed the agility test (Illinois agility run). Subjects performed two trials for

Table 2 Match and training details for junior and senior rugby league players

\begin{tabular}{lllll}
\hline Team & $\begin{array}{l}\text { Matches } \\
\text { played }\end{array}$ & $\begin{array}{l}\text { Match } \\
\text { duration }\end{array}$ & $\begin{array}{l}\text { Training } \\
\text { sessions a } \\
\text { week }\end{array}$ & $\begin{array}{l}\text { Training } \\
\text { session } \\
\text { duration (min) }\end{array}$ \\
\hline First grade & 8 & $76.3^{*}$ & 2 & 90 \\
Second grade & 9 & $65.6^{*}$ & 2 & 90 \\
Under 19 & 10 & 60.0 & 2 & 90 \\
Under 16 & 7 & 60.0 & 2 & 90 \\
Under 15 & 7 & 60.0 & 2 & 90 \\
Under 14 & 8 & 60.0 & 2 & 70 \\
Under 13 & 8 & 60.0 & 2 & 60
\end{tabular}

*At the time of the field testing, first grade players had competed in six 80 minute matches, one 70 minute match, and one 60 minute match. Second grade players had competed in five 70 minute matches and four 60 minute matches. the speed, muscular power, and agility tests, with a recovery of three to five minutes between trials. Players were encouraged to perform low intensity activities and stretches between trials to minimise reductions in performance. They were required to complete speed and agility tests in football boots. Upon completion of the respective tests, each group rotated until all tests had been performed. The field testing session was concluded with subjects performing the multistage fitness test (estimated $\left.\dot{\mathrm{V}}_{2} \mathrm{MAX}\right)$. To standardise conditions between teams, the same investigator conducted the same test for each individual team.

\section{Muscular power}

Lower leg muscular power was evaluated by means of the vertical jump test. ${ }^{16} \mathrm{~A}$ board, covering a $150 \mathrm{~cm}$ vertical distance, was mounted to a wall during the vertical jump test. Subjects were requested to stand with their feet flat on the ground, extend one arm and hand, and mark with chalk the highest point reached. They were asked to hold the chalk between the tips of the index and middle fingers. Each subject was instructed to spring upward from a crouch position and touch the wall mounted board at the highest possible point. No specific instructions were given about the depth or speed of the countermovement. ${ }^{16}$ Vertical jump height was calculated as the distance from the highest point reached during standing and the highest point reached during the vertical jump. Vertical jump height was measured to the nearest $0.1 \mathrm{~cm}$, with the highest value obtained from two trials used as the vertical jump score. The intraclass correlation coefficient for test-retest reliability and technical error of measurement for the vertical jump test was 0.93 and $4.54 \%$ respectively. ${ }^{15}$

\section{Speed}

Running speed was evaluated from a $10 \mathrm{~m}, 20 \mathrm{~m}$, and $40 \mathrm{~m}$ sprint $^{10}{ }^{11}$ using electronic timing gates (Speed Light model TB4, serial no 4921001; Southern Cross University Technical Services, Lismore, Australia). The timing gates were positioned 10, 20, and $40 \mathrm{~m}$ cross wind from a predetermined starting point. On the command "Go", subjects sprinted from a standing start. ${ }^{10}$ They were instructed to run as quickly as possible along the $40 \mathrm{~m}$ distance. Speed was measured to the nearest 0.01 second, with the fastest value obtained from two trials used as the speed score. The intraclass correlation coefficient for test-retest reliability and technical error of measurement for the $10 \mathrm{~m}, 20 \mathrm{~m}$, and $40 \mathrm{~m}$ sprint tests were $0.88,0.89$, and 0.92 , and $2.07 \%, 1.52 \%$, and $1.25 \%$ respectively. ${ }^{15}$

\section{Agility}

Agility was assessed using the Illinois agility run. ${ }^{17}$ On the command "Go", subjects sprinted $9 \mathrm{~m}$, turned, and returned to the starting line. After returning to the starting line, they swerved in and out of four markers, completing two $9 \mathrm{~m}$ sprints to finish the agility course. Times were recorded using a hand held stopwatch to the nearest 0.01 second. The fastest value obtained from two trials was used as the agility score. The intraclass correlation coefficient for test-retest reliability and technical error of measurement for the Illinois agility run were 0.86 and $2.02 \%$ respectively. ${ }^{15}$

\section{$\dot{\mathrm{V}}_{\mathrm{O}_{2} \mathrm{MAX}}$}

$\dot{\mathrm{V}}_{2} \mathrm{MAX}$ was estimated using the multistage fitness test. ${ }^{18}$ Subjects were required to run back and forth-that is, shuttle run-along a $20 \mathrm{~m}$ track, keeping in time with a series of signals on an audiocassette. The frequency of the audible signals (and hence running speed) was progressively increased, until subjects reached volitional exhaustion. The multistage fitness test tape was calibrated before each test in accordance with procedures outlined by the Australian Coaching Council. ${ }^{18}$ $\dot{\mathrm{V}}_{2}$ MAX was estimated using regression equations described by 
Table 3 Age, body mass, and playing experience of junior and senior rugby league forwards and backs

\begin{tabular}{|c|c|c|c|c|c|c|}
\hline & \multicolumn{2}{|l|}{ Age (years) } & \multicolumn{2}{|c|}{ Playing experience (years) } & \multicolumn{2}{|l|}{ Body mass $(\mathrm{kg})$} \\
\hline & Forwards & Backs & Forwards & Backs & Forwards & Backs \\
\hline First grade & $25.1(23.0 \text { to27.2) })^{\circ}$ & $23.4(20.9+025.9)$ & $19.1(16.0+22.2)^{\circ}$ & 16.2 (13.1 to 19.3) & $91.9(85.3+098.5)^{a}$ & $88.6(84.4 \uparrow \circ 92.8)$ \\
\hline Second grade & $23.8(22.0 \text { to } 25.6)^{b}$ & 21.9 (19.5to24.3) & $15.2(12.2 \mathrm{to} 18.2)^{\mathrm{b}}$ & $13.0(8.8$ to 17.2$)$ & $99.2(92.9 \text { to } 105.5)^{b *}$ & 82.4 (78.8to86.0) \\
\hline Under 19 & $17.8(17.2 \mathrm{to} 18.4)^{\mathrm{bbc}}$ & $17.3(16.8+017.8)$ & $10.4(8.6 \text { to } 12.2)^{\mathrm{ac}}$ & $9.2(7.1$ to 11.3$)$ & $89.4(78.6 \text { to } 100.2)^{c}$ & $74.2(67.7$ to 80.7$)$ \\
\hline Under 16 & $15.4(15.1 \text { to } 15.7)^{\text {bbd }}$ & $15.6(15.3 \mathrm{to} 15.9)$ & $7.5(5.1 \text { to9.9 })^{\mathrm{ob}}$ & $8.9(6.9$ to 10.9$)$ & $75.5(68.9 \text { to } 82.1)^{\mathrm{bbd}}$ & $64.8(60.2+069.4)$ \\
\hline Under 15 & $14.5(14.2 \mathrm{to} 14.8)^{\mathrm{abc}}$ & 14.6 (14.3to 14.9) & $6.6(4.8 \text { to } 8.4)^{\mathrm{ab}}$ & 6.1 (3.8 to 8.4$)$ & 76.5 (70.0to 83.0$)^{\text {bbe * }}$ & $62.1(57.7$ to 66.5$)$ \\
\hline Under 14 & 13.5 (13.0to 14.0) $)^{\mathrm{abc}}$ & $13.7(13.4 \mathrm{to} 14.0)$ & $6.1(3.3 \text { to } 8.9)^{\mathrm{ab}}$ & 5.8 (3.8 to 7.8$)$ & $67.7(57.5 \text { to } 77.9)^{\mathrm{abc}}$ & $52.1\left(47.4 \mathrm{to}^{2} 56.8\right)$ \\
\hline Under 13 & $12.5(12.2 \mathrm{to} 12.8)^{\mathrm{bbcd}}$ & 12.3 (12.0tol2.6) & $4.7(3.2 \text { to } 6.2)^{\text {abc }}$ & 3.4 (1.9 to 4.9$)$ & $57.0(49.0 \text { to } 65.0)^{0 \text { bbcde }}$ & $44.8(41.5$ to 48.1$)$ \\
\hline
\end{tabular}

Values are reported as means $(95 \% \mathrm{Cl}$. Significant team differences $(\mathrm{p}<0.05)$ between like superscripts. * Forwards significantly different $(p<0.05)$ from backs. Forwards $(n=80 ;$ first grade, $n=11 ;$ second grade, $n=16$; under 19 , $n=10$; under $16, n=12$; under $15, n=11$; under $14, n=7$; under $13, n=13)$. Backs $(n=79$; first grade, $n=9$; second grade, $n=13$; under 19, $n=12 ;$ under $16, n=9 ;$ under $15, n=12 ;$ under $14, n=10 ;$ under $13, n=14)$.

Table 4 Times for the $10 \mathrm{~m}, 20 \mathrm{~m}$, and $40 \mathrm{~m}$ sprint for junior and senior rugby league forwards and backs

\begin{tabular}{|c|c|c|c|c|c|c|}
\hline & \multicolumn{2}{|l|}{$10 \mathrm{~m}(\mathrm{~s})$} & \multicolumn{2}{|l|}{$20 \mathrm{~m}(\mathrm{~s})$} & \multicolumn{2}{|l|}{$40 \mathrm{~m}(\mathrm{~s})$} \\
\hline & Forwards & Backs & Forwards & Backs & Forwards & Backs \\
\hline First grade & $2.05(1.97 \text { to } 2.13)^{\circ}$ & 1.98 (1.93 to 2.03 ) & $3.38(3.28 \text { to } 3.48)^{\circ}$ & 3.28 (3.21 to 3.35 ) & $5.86(5.76 \text { to } 5.96)^{\mathrm{a}}$ & 5.69 (5.58 to 5.80$)$ \\
\hline Second grade & $2.14(2.09 \text { to } 2.19)^{b}$ & $2.08(1.97$ to 2.19$)$ & $3.50(3.43 \text { to } 3.57)^{b}$ & $3.34(3.22$ to 3.46$)$ & $6.09(5.94 \text { to } 6.24)^{b}$ & 5.81 (5.64 to 5.98$)$ \\
\hline Under 19 & $2.19(2.10 \text { to } 2.28)^{\mathrm{acc}}$ & 2.19 (2.09 to 2.29$)$ & $3.57(3.46 \text { to } 3.68)^{\mathrm{c}}$ & $3.53(3.41$ to 3.65$)$ & $6.20(6.01 \text { to } 6.39)^{\mathrm{c}}$ & $6.01(5.85$ to 6.17$)$ \\
\hline Under 16 & $2.22(2.15 \text { to } 2.29)^{\text {dd }}$ & $2.17(2.10$ to 2.24$)$ & $3.61(3.51 \text { to } 3.71)^{\text {od }}$ & 3.55 (3.46 to 3.64$)$ & $6.17(6.00 \text { to } 6.34)^{d}$ & $6.00(5.87$ to 6.13$)$ \\
\hline Under 15 & $2.25(2.20 \text { to } 2.30)^{\text {ae }}$ & 2.21 (2.13 to 2.29$)$ & $3.72(3.61 \text { to } 3.83)^{\text {abe }}$ & 3.62 (3.53 to 3.71 ) & $6.58(6.32 \text { to } 6.84)^{\text {abe }}$ & $6.26(6.14$ to 6.38$)$ \\
\hline Under 14 & $2.44(2.34 \text { to } 2.54)^{\text {bbf }}$ & 2.24 (2.15 to 2.33$)$ & $3.99(3.79 \text { to } 4.19)^{\text {bbcf }}$ & 3.70 (3.51 to 3.89 ) & $7.00(6.40 \text { to } 7.60)^{\text {abcodf }}$ & $6.47(6.08$ to 6.86$)$ \\
\hline Under 13 & $2.60(2.53 \text { to } 2.67)^{\text {abcdef }}$ & $2.46(2.38$ to 2.54$)$ & $4.24(4.14 \text { to } 4.34)^{\text {bbcdef }}$ & $4.04(3.92$ to 4.16$)$ & $7.50(7.29 \text { to } 7.71)^{\text {abcdef }}$ & 7.11 (6.87 to 7.35$)$ \\
\hline
\end{tabular}

Values are reported as means $(95 \% \mathrm{Cl})$. Significant team differences $(\mathrm{p}<0.05)$ between like superscripts. Forwards $(\mathrm{n}=80 ;$ first grade, $\mathrm{n}=11 ;$ second grade, $\mathrm{n}=16 ;$ under $19, \mathrm{n}=10$; under $16, \mathrm{n}=12 ;$ under $15, \mathrm{n}=11$; under $14, \mathrm{n}=7$; under $13, n=13)$. Backs $(n=79$; first grade, $n=9$; second grade, $n=13$; under 19, $n=12$; under $16, n=9$; under $15, n=12$; under 14, $n=10 ;$ under 13 , $n=14)$.

Table 5 Vertical jump, agility, and estimated $\dot{V}_{2} \mathrm{MAX}$ for junior and senior rugby league forwards and backs

\begin{tabular}{|c|c|c|c|c|c|c|}
\hline & \multicolumn{2}{|l|}{ Vertical jump (cm) } & \multicolumn{2}{|l|}{ Agility (s) } & \multicolumn{2}{|l|}{$\dot{\mathrm{V}}_{2} \operatorname{MAX}(\mathrm{ml} / \mathrm{kg} / \mathrm{min})$} \\
\hline & Forwards & Backs & Forwards & Backs & Forwards & Backs \\
\hline First grade & $48.7(42.1 \text { to } 55.3)^{a}$ & $50.9(47.5$ to 54.3$)$ & $17.2(16.6 \text { to } 17.8)^{\circ}$ & 17.4 (16.7 to 18.1$)$ & $50.0(47.6 \text { to } 52.4)^{\mathrm{a}}$ & 50.1 (47.4 to 52.8 ) \\
\hline Second grade & $41.0(37.8 \text { to } 44.2)^{\mathrm{b}}$ & $42.9(39.3$ to 46.5$)$ & $18.1(17.6 \text { to } 18.6)^{b}$ & $17.7(17.3$ to 18.1$)$ & $45.5(42.8 \text { to } 48.2)^{b}$ & $45.0(41.5$ to 48.5$)$ \\
\hline Under 19 & $37.9(33.1 \text { to } 42.7)^{\mathrm{ac}}$ & $40.0(35.1$ to 44.9$)$ & $18.3(17.5 \text { to } 19.1)^{\mathrm{c}}$ & $17.9(17.2$ to 18.6$)$ & $43.9(40.3 \text { to } 47.5)^{c}$ & 46.1 (42.3 to 49.9 ) \\
\hline Under 16 & $38.0(34.4 \text { to } 41.6)^{\text {jd }}$ & $41.2(37.7$ to 44.7$)$ & $19.4(18.5 \text { to } 20.3)^{\text {bbd }}$ & 19.1 (18.4 to 19.8) & $42.9(40.1 \text { to } 45.7)^{\mathrm{d} *}$ & 49.5 (46.4 to 52.6 ) \\
\hline Under 15 & $34.7(29.2 \text { to } 40.2)^{\mathrm{a}}$ & 37.1 (34.3 to 39.9$)$ & $19.5(18.5 \text { to } 20.5)^{\text {bbce }}$ & 19.5 (18.9 to 20.1 ) & $38.5(35.5 \text { to } 41.5)^{a}$ & 41.4 (38.7 to 44.1$)$ \\
\hline Under 14 & $33.1(26.8 \text { to } 39.4)^{\circ}$ & 38.5 (32.7 to 44.3$)$ & $21.1(19.4 \text { to } 22.8)^{\text {bbc }}$ & 20.3 (19.4 to 21.2 ) & $40.5(35.5 \text { to } 45.5)^{\circ}$ & $40.8(37.0$ to 44.6$)$ \\
\hline Under 13 & $28.2(21.7 \text { to } 34.7)^{\text {bbcd }}$ & $30.8(28.2$ to 33.4$)$ & $22.0(21.5 \text { to } 22.5)^{\text {abcde }}$ & 21.5 (20.9 to 22.1$)$ & $32.1(29.6 \text { to } 34.6)^{\mathrm{abcd}}$ & 36.2 (33.8 to 38.6$)$ \\
\hline
\end{tabular}

Values are reported as means $(95 \% \mathrm{Cl})$. Significant team differences $(\mathrm{p}<0.05)$ between like superscripts. * Forwards significantly different $(\mathrm{p}<0.05)$ from backs. Forwards $(\mathrm{n}=80 ;$; first grade, $\mathrm{n}=11$; second grade, $\mathrm{n}=16$; under 19 , $n=10$; under 16, $n=12$; under 15, $n=11$; under 14, $n=7$; under 13, $n=13$ ). Backs $(n=79$; first grade, $n=9$; second grade, $n=13$; under 19, $n=12 ;$ under 16, $n=9$; under 15, $n=12$; under 14, $n=10$; under 13, $n=14)$. 
Table 6 Multiple logistic regression analysis to predict suitability of players as forwards or backs

\begin{tabular}{|c|c|c|c|c|}
\hline & $\begin{array}{l}\text { Regression } \\
\text { coefficient }\end{array}$ & SE & Odds ratio $(95 \% \mathrm{Cl})$ & $\mathrm{p}$ Value \\
\hline \multicolumn{5}{|l|}{ Model 1} \\
\hline Age (years) & 0.2581 & 0.12 & $1.3(1.03$ to 1.63$)$ & 0.0295 * \\
\hline Playing experience (years) & -0.1113 & 0.08 & $0.90(0.77$ to 1.05$)$ & 0.1601 \\
\hline Body mass $(\mathrm{kg})$ & -0.1438 & 0.03 & $0.87(0.81$ to 0.92$)$ & 0.0001 * \\
\hline $10 \mathrm{~m}(\mathrm{~s})$ & -1.3802 & 8.01 & $0.25(0.00$ to 1646093.00$)$ & 0.8631 \\
\hline $20 \mathrm{~m}(\mathrm{~s})$ & 4.7257 & 9.85 & $112.81\left(0.00\right.$ to $\left.2.76^{10}\right)$ & 0.6315 \\
\hline $40 \mathrm{~m}(\mathrm{~s})$ & -4.3220 & 3.22 & $0.01(0.00$ to 7.26$)$ & 0.1791 \\
\hline Vertical jump (cm) & 0.0207 & 0.04 & $1.02(0.95$ to 1.10$)$ & 0.5693 \\
\hline Agility (s) & 0.2922 & 0.23 & $1.34(0.85$ to 2.12$)$ & 0.2118 \\
\hline$\dot{\mathrm{V}}_{2} \operatorname{MAX}(\mathrm{ml} / \mathrm{kg} / \mathrm{min})$ & 0.0274 & 0.05 & $1.03(0.93$ to 1.14$)$ & 0.5953 \\
\hline \multicolumn{5}{|l|}{ Model 2} \\
\hline Age (years) $\times$ body mass $(\mathrm{kg})$ & -0.0009 & 0.0003 & $0.999(0.998$ to 1.00$)$ & $0.0019 *$ \\
\hline
\end{tabular}

Ramsbottom et al. ${ }^{19}$ When compared with treadmill determined $\dot{\mathrm{V}}_{2} \mathrm{MAX}$, it has been shown that the multistage fitness test provides a valid estimate of $\dot{\mathrm{V}}_{\mathrm{O}_{2} \mathrm{MAX}} .^{19}$ In addition, all senior players completed duplicate multistage fitness tests, performed one week apart, before the start of preseason training. The intraclass correlation coefficient for test-retest reliability and technical error of measurement for the multistage fitness test were 0.92 and $4.62 \%$ respectively.

\section{Statistical analysis}

Data were collected from 80 forwards (23 props, 14 hookers, 27 second rows, 16 locks) and 79 backs ( 13 halfbacks, 11 fiveeighths, 15 centres, 30 wings, 10 fullbacks). Table 1 shows the distribution of participating subjects. Differences in the physiological characteristics among teams were compared using a one way analysis of variance. When required, comparisons of group means were performed using a Scheffe's post hoc test. Differences in the physiological characteristics of forwards and backs for each team were compared using independent $t$ tests and the Bonferroni adjustment. Multiple logistic regression analysis was performed to determine if any physiological variables could predict the suitability of players as forwards or backs. The level of significance was set at $\mathrm{p}<0.05$, and data are reported as means and $95 \%$ confidence intervals $(\mathrm{CI})$.

\section{RESULTS}

Training and match frequency of junior and senior players

At the time of the field testing, players had competed in 7-10 matches for the season. Matches were 60-80 minutes in duration. All senior players (first grade, second grade, and under 19) participated in two 90 minute training sessions a week, and junior players participated in two 60 minute (under 13), 70 minute (under 14), or 90 minute (under 15, under 16) training sessions a week (table 2).

\section{Age, playing experience, and body mass of junior and senior players}

Table 3 shows the playing experience, age, and body mass of the junior and senior players. As expected, there was a significant effect $(\mathrm{p}<0.05)$ of age and playing level on playing experience and body mass. First grade players were significantly $(\mathrm{p}<0.05)$ older and had greater playing experience than all players, except second grade players. No significant differences were detected among senior teams for body mass. However, players within the second grade team were significantly $(p<0.05)$ heavier than all junior players. There were no significant differences between forwards and backs for age and playing experience. Although forwards were heavier than backs for all teams, the difference was only significant $(\mathrm{p}<0.05)$ for second grade and under 15 players.

Muscular power, speed, agility, and estimated $\dot{V}_{\mathrm{O}_{2}} \operatorname{MAX}$ of junior and senior players

Tables 4 and 5 show the mean (95\% CI) results for muscular power (vertical jump), speed ( $10 \mathrm{~m}, 20 \mathrm{~m}$, and $40 \mathrm{~m}$ ), agility (Illinois agility run), and estimated $\dot{\mathrm{V}}_{2} \mathrm{MAX}$ tests (multistage fitness test), for junior and senior players. There was a significant effect $(p<0.05)$ of age and playing level on muscular power, speed, agility, and estimated $\dot{\mathrm{V}}_{2} \mathrm{MAX}$, with the physiological capacities of players increasing as the playing level increased. Scores for vertical jump and agility were not significantly different between forwards and backs for any of the junior or senior teams. Although backs were faster than forwards during the $10 \mathrm{~m}, 20 \mathrm{~m}$, and $40 \mathrm{~m}$ sprint, differences between forwards and backs were not significantly different for any of the teams tested. Under 16 backs had significantly higher $(\mathrm{p}<0.05)$ estimated $\dot{\mathrm{V}}_{2} \mathrm{MAX}$ than forwards.

\section{Multiple logistic regression analysis}

Table 6 shows the multiple logistic regression analysis that was developed to predict which players would be suitable as forwards or backs. Body mass and age were the only variables that contributed significantly $(\mathrm{p}<0.05)$ to the predictive model.

\section{DISCUSSION}

Although previous studies have investigated the physiological profiles of amateur, ${ }^{14}$ semiprofessional, ${ }^{15}$ and professional ${ }^{80-13}$ rugby league players, no study has investigated the physiological characteristics of junior and senior rugby league players competing at the subelite level. These results show that there is a progressive improvement in the physiological capacities of rugby league players as the playing level increases. Furthermore, they extend the findings from professional rugby league players $^{8}{ }^{10-13}$ by providing normative data and performance standards for subelite junior and senior rugby league players. Coaches and sports scientists may also use the present results as a tool for talent identification in rugby league. Although the physiological characteristics of these subjects provide performance standards to assist the identification of rugby league talent, several other factors-for example, sociological, physical, psychological, and personal-may also influence ability to play competitive team sport. ${ }^{20}$ These factors should be considered when developing talent identification programmes for rugby league. In addition, although playing performance may be related to the physiological capacities of players, improved fitness may not always equate to improved performance. ${ }^{21}$ With this in mind, future studies attempting to identify rugby 
league talent should include a skills performance test that assesses a player's ability to use developed skills and make decisions under low pressure, high pressure, and fatigued situations. ${ }^{15} 2223$

In this study, higher muscular power, agility, speed, and $\dot{\mathrm{V}}_{2} \operatorname{MAX}$ were found in senior teams than junior teams. These findings are consistent with most previous studies on other team sports (such as Australian football, soccer, and field hockey) which have found higher physiological capacities as the playing level increased. ${ }^{16}{ }^{24}{ }^{25}$ However, although the different physiological capacities between junior and senior teams are consistent with findings from Australian football, soccer, and field hockey, most of the previous studies were conducted on elite athletes. As a result, the physiological capacities of the present sample of subelite junior and senior rugby league players are considerably lower than those from other team sports. In addition, the relative difference $(24.0 \%$ to $40.3 \%)$ in muscular power, agility, speed, and $\dot{\mathrm{V}}_{2} \mathrm{MAX}$ between the junior and senior teams of this study was considerably greater than previously reported for other team sport athletes $(0.3 \%$ to $15.2 \%) .{ }^{162425}$ The smaller relative differences in the physiological capacities of elite junior and senior Australian football, ${ }^{24}$ soccer, ${ }^{16}$ and field hockey players ${ }^{25}$ may reflect a greater access to specialised coaching and conditioning for both junior and senior competitors of these sports.

This study found a progressive improvement in agility, speed, muscular power, and $\dot{\mathrm{V}}_{2} \mathrm{MAX}$ scores with increasing age and playing level. In addition, playing experience and body mass also progressively increased from junior players through to senior players. It is likely that the improvement in physiological capacities from junior to senior players reflects a normal adaptation associated with the onset of puberty and moderate increases in age. However, it is also possible that the progressive improvement in physiological capacities from under 13 players through to first grade players is due to the greater training load and higher playing intensity at the higher playing level. Indeed, the longer matches and training sessions (table 2) and higher match intensity ${ }^{26}{ }^{27}$ experienced by senior players may explain, at least in part, their superior physiological capacities. The recent finding of no significant differences in preseason muscular power, agility, speed, and $\dot{\mathrm{V}}_{\mathrm{O}_{2} \mathrm{MAX}}$ scores between first grade and second grade players, ${ }^{15}$ despite considerable ( $2.7 \%$ to $18.4 \%$ ) differences in these variables during the competitive phase of the season in the present study (tables 4 and 5), lends support to the hypothesis that the duration and intensity of matches has an important effect on the physiological capacities of rugby league players.

The subjects in this study trained for two days a week and played one 60 minute (under 13-under 19), 70 minute (second grade), or 80 minute (first grade) match every seven days. The training and match frequencies are similar to those of senior amateur rugby league players, ${ }^{14}$ but lower than those described for professional rugby league players. ${ }^{26}{ }^{28}$ Although the physiological characteristics of the senior rugby league players in this study are lower than those of professional players ${ }^{811}$ the present results are superior to those reported for amateur rugby league players. In addition, the speed, muscular power, and $\dot{\mathrm{V}}_{2} \mathrm{MAX}$ results for the junior players are similar (under 14, under 15) or superior (under 16) to those reported for amateur rugby league players. ${ }^{14}$ Given the similar training and match frequencies of the present subjects and amateur rugby league players, ${ }^{14}$ the superior physiological characteristics of the present subjects are probably due to a higher intensity of training sessions and matches. However, given the relatively moderate- that is, two days a week-training frequency of the present participants, it is possible that elite-for example, representative-junior and senior players would have superior physiological characteristics to the present sample of subelite junior and senior players. Nevertheless, the present results can be used as a guide to objectively monitor improvements in the physical fitness of subelite junior and senior rugby league players.

\section{Take home message}

This study found significant differences in the physiological capacities of subelite junior and senior rugby league players. These findings provide normative data and performance standards for rugby league forwards and backs competing at the subelite level.

Consistent with previous results from amateur, ${ }^{14}$ semiprofessional, ${ }^{15}$ and professional ${ }^{811}$ rugby league players, this study found higher body mass in forwards than backs. In addition, body mass was a significant predictor in correctly classifying players as either a forward or back. These findings emphasise the importance of large body size in dominating the ruck and tolerating the heavy tackles and collisions associated with forward positions. Of interest were the lack of consistent significant differences between forwards and backs for the $10 \mathrm{~m}, 20 \mathrm{~m}$, and $40 \mathrm{~m}$ speed tests. Previous studies have reported similar $10 \mathrm{~m}$ sprint times between forwards and backs, with backs having significantly faster $20 \mathrm{~m}$ and $40 \mathrm{~m}$ speed than forwards. ${ }^{10}{ }^{11}{ }^{14}$ These findings have been attributed to the rare requirement of forwards to run further than $10 \mathrm{~m}$ in a single bout of intense activity. ${ }^{8}$ However, recent time and motion studies of rugby league matches played under the 10 $m$ defensive rule have shown that forwards are required to run $49-50 \%$ further than previously required under the $5 \mathrm{~m}$ defensive rule. ${ }^{29}$ These findings may suggest that forwards have adapted to the further running distances required for the modern game, or conditioning coaches have modified training programmes to develop a greater sprinting ability in forwards.

This finding of higher estimated $\dot{\mathrm{V}}_{2} \mathrm{MAX}$ in under 16 backs than forwards is consistent with some, ${ }^{11}$ but not all ${ }^{14}$ studies of senior rugby league players. It may be expected given that backs have been shown to run further than forwards during a competitive rugby league match. ${ }^{30}$ Although differences in aerobic fitness between forwards and backs may be expected, it is unclear why significant differences were only observed in under 16 players. The lower estimated $\dot{\mathrm{V}}_{2} \mathrm{MAX}$ in forwards may suggest that aerobic fitness training was neglected in these athletes in order to train other physiological parameters, such as speed, muscular power, or agility. ${ }^{11}$ However, this possibility appears unlikely given the similar speed, muscular power, and agility between forwards and backs. It is possible that the duration of the training stimulus used by forwards was not enough to induce sufficient peripheral and/or central adaptations for improvements in $\dot{\mathrm{V}}_{2} \mathrm{MAx}$. Alternatively, the low estimated $\dot{\mathrm{V}}_{2} \mathrm{MAX}$ in the under 16 forwards of this study suggests that the volume and intensity of training may differ between forwards and backs in this age group. ${ }^{14}$

Several studies have documented a higher incidence of injury as the playing level increases, suggesting that playing intensity has an effect on injury rates in rugby league. ${ }^{126}{ }^{27}$ In addition, it has recently been shown that the incidence of junior rugby league injuries progressively increases from age 6 through to age $17 .{ }^{31}$ Interestingly, it has been shown that the incidence of injury is increased from 5.3 per 1000 playing hours between the ages of 6 and 12, to 14.9 per 1000 playing hours at age $13 .{ }^{31}$ The incidence of injury in senior rugby league players has been shown to be in the range $26.8-52.3$ per 1000 playing hours, ${ }^{76-283233}$ with professional rugby league players having higher injury rates than their amateur counterparts. ${ }^{122}$ Given the progressive improvements in speed, muscular power, agility, and $\dot{\mathrm{V}}_{2} \mathrm{MAX}$ with the higher playing level in this study (tables 4 and 5), the progressive rise in injury rates reported previously is to be expected. The high aerobic fitness of senior players relative to junior players would allow greater recovery between high intensity bouts of activity and therefore a higher overall match intensity. In addition, the 
greater speed, muscular power, and body mass of senior players would contribute to greater impact forces in tackles, and perhaps contribute to the higher injury rates of senior players. However, at present there is little scientific evidence to support the hypothesis that physiological capacities influence the injury rates of rugby league players. Clearly, further studies investigating the influence of physiological capacities on the incidence of injuries in junior and senior rugby league players are warranted

Although body mass and age were the only variables to contribute to the classification of players into their correct position, it is possible that other physiological variables may have added to the predictive power of the logistic regression model. Strength, ${ }^{811}$ phosphate recovery, ${ }^{11}$ and flexibility ${ }^{11}$ are physiological parameters that have been identified as important qualities used by rugby league players. Furthermore, anthropometric measurements-for example, height, sum of skinfolds ${ }^{11}{ }^{14}$-may have provided a more complete description of the physical characteristics of the present sample of junior and senior rugby league players. However, although further field tests may have provided additional information on the physiological and anthropometric characteristics of junior and senior rugby league players, the time and personnel available limited the number of tests included in the field testing battery.

In conclusion, the results of this study show that there is a progressive improvement in the physiological capacities of rugby league players as the playing level increases. Furthermore, the findings provide normative data and performance standards for subelite junior and senior rugby league players. Further studies investigating the sociological, physical, psychological, and personal predictors of talent in rugby league are warranted.

\section{REFERENCES}

1 Gabbett TJ. Incidence, site, and nature of injuries in amateur rugby league over three consecutive seasons. Br J Sports Med 2000;34:98-103.

2 Gabbett TJ. Incidence of injury in amateur rugby league sevens. $\mathrm{Br} J$ Sports Med 2001;36:23-6.

3 Gabbett TJ. Training injuries in rugby league: an evaluation of skill-based conditioning games. J Strength Cond Res 2001;16:236-41.

4 Brewer J, Davis J. Applied physiology of rugby league. Sports Med 1995;20:129-35.

5 Meir R, Newton R, Curtis $E$, et al. Physical fitness qualities of professional rugby league football players: determination of positional differences. J Strength Cond Res 2001;15:450-8.

6 Douge B. Football: the common threads between the games. In: Reilly $T$ Lees A, Davids K, et al, eds. Science and football: proceedings of the first world congress of science and football. New York: E and FN Spoon, 1987:3-19.

7 Gibbs N. Injuries in professional rugby league: a three-year prospective study of the South Sydney professional rugby league football club. Am J Sports Med 1993;21:696-700.
8 Meir $\mathbf{R}$. Evaluating players fitness in professional rugby league: reducing subjectivity. Strength and Conditioning Coaching 1993;1:11-17.

9 Baker D, Nance S. The relation between running speed and measures of strength and power in professional rugby league players. J Strength Cond Res 1999;13:230-5.

10 Brewer J, Davis J, Kear J. A comparison of the physiological characteristics of rugby league forwards and backs. J Sports $S_{c i}$ 1994; 12:158.

11 O'Connor D. Physiological characteristics of professional rugby league players.Strength and Conditioning Coaching 1996;4:21-6.

12 Larder P. The rugby league coaching manual. 2nd ed. London: Kingswood Press, 1992.

13 O'Connor D. Fitness profile of professional Rugby League players. J Sports Sci 1995;13:505

14 Gabbett TJ. Physiological and anthropometric characteristics of amateur rugby league players. Br J Sports Med 2000;34:303-7.

15 Gabbett TJ. Influence of physiological characteristics on selection in a semi-professional rugby league team: a case study. J Sports Sci 2001;20:399-405.

16 Ellis L, Gastin P, Lawrence S, et al. Protocols for the physiological assessment of team sport players. In: Gore CJ, ed. Physiological tests for elite athletes. Champaign, IL: Human Kinetics, 2000:128-44.

17 Hastad DN, Lacy AC. Measurement and evaluation in physical education and exercise science. 2nd ed. Scottsdale, AZ: Gorsuch education and exercise science.
Scarisbrick, Publishers, 1994.

18 Australian Coaching Council. Multistage fitness test. A progressive shuttle-run test for the prediction of maximum oxygen uptake. Belconnen, ACT, Australia: Australian Sports Commission, 1988.

19 Ramsbottom R, Brewer J, Williams C. A progressive shuttle run test to estimate maximal oxygen uptake. Br J Sports Med 1988;22:141-4.

20 Williams AM, Reilly T. Talent identification and development in soccer. $J$ Sports Sci 2000; 18:657-67.

21 Gabbett T. Performance, fatigue, and injuries in rugby league. Rugby League Coaching Manuals 2001;22:22-6.

22 Gabbett TJ. Severity and cost of injuries in amateur rugby league: a case study. J Sports Sci 2001;19:341-7.

23 Gabbett T. Increasing training intensity in country rugby league players. Rugby League Coaching Magazine 2001;20:30-1.

$24 \mathrm{Keogh} \mathrm{J}$. The use of physical fitness scores and anthropometric data to predict selection in an elite under 18 Australian rules football team. J Sci Med Sport 1999;2:125-33.

25 Lawrence S, Polglaze T. Protocols for the physiological assessment of male and female field hockey players. In: Gore CJ, ed. Physiological tests for elite athletes. Champaign, IL: Human Kinetics, 2000:286-301.

26 Stephenson S, Gissane C, Jennings D. Injury in rugby league: a four year prospective study. Br J Sports Med 1996;30:331-4.

27 Gissane C, Jennings DC, Standing P. Incidence of injury in rugby league football. Physiotherapy 1993;79:305-10.

28 Hodgson Phillips L, Standen PJ, Batt ME. Effects of seasonal change in rugby league on the incidence of injury. $\mathrm{Br} J$ Sports Med 1998:32:144-8.

29 Meir R, Colla P, Milligan C. Impact of the 10 meter rule change on professional rugby league: implications for training. Strength and Conditioning 2001;23:42-6.

30 Meir R, Arthur D, Forrest M. Time and motion analysis of professional rugby league: a case study. Strength and Conditioning Coaching $1993 ; 1: 24-9$.

31 Raftery $M$, Parker R, Stacey $E$, et al. Incidence of injury in junior rugby league in the Penrith and District junior rugby league area. Children's Hospital Institute of Sports Medicine, Research and Development Office, The New Children's Hospital, Westmead 1999:1-22.

32 Estell J, Shenstone B, Barnsley L. Frequency of injuries in different age-groups in an elite rugby league club. Aust J Sci Med Sport 1995;27:95-7.

33 Seward H, Orchard J, Hazard H, et al. Football injuries in Australia at the elite level. Med J Aust 1993;159:298-301. 